\title{
TRPC5 regulates axonal outgrowth in developing retinal ganglion cells
}

\author{
Mai Oda ${ }^{1} \cdot$ Hanako Yamamoto ${ }^{1} \cdot$ Hidetaka Matsumoto $^{2} \cdot$ Yasuki Ishizaki $^{1} \cdot$ Koji Shibasaki $\mathbb{C}^{1}$
}

Received: 22 July 2019 / Revised: 15 November 2019 / Accepted: 15 November 2019 / Published online: 16 December 2019

(c) The Author(s), under exclusive licence to United States and Canadian Academy of Pathology 2019

\begin{abstract}
The TRPC5 ion channel is activated upon depletion of intracellular calcium stores, as well as by various stimuli such as nitric oxide (NO), membrane stretch, and cold temperatures. TRPC5 is abundantly expressed in the central nervous system where it has important neuronal functions. In the chick retina, TRPC5 expression was shown to be restricted to amacrine cells (ACs) and Müller glial cells, although its expression was also observed in the ganglion cell layer (GCL) in displaced ACs, as determined by their characteristic cell morphology. However, it is possible that this expression analysis alone might be insufficient to fully understand the expression of TRPC5 in retinal ganglion cells (RGCs). Hence, we analyzed TRPC5 expression by in situ hybridization and immunostaining in the developing mouse retina, and for the first time identified that developing and mature RGCs strongly express TRPC5. The expression begins at E14.5, and is restricted to ACs and RGCs. It was reported that TRPC5 negatively regulates axonal outgrowth in hippocampal neurons. We thus hypothesized that TRPC5 might have similar functions in RGCs since they extend very long axons toward the brain, and this characteristic significantly differs from other retinal cell types. To elucidate its possible involvement in axonal outgrowth, we inhibited TRPC5 activity in developing RGCs which significantly increased RGC axon length. In contrast, overexpression of TRPC5 inhibited axonal outgrowth in developing RGCs. These results indicate that TRPC5 is an important negative regulator of RGC axonal outgrowth. Since TRPC5 is a mechanosensor, it might function to sense abnormal intraocular pressure changes, and could contribute to the death of RGCs in diseases such as glaucoma. In this case, excessive $\mathrm{Ca}^{2+}$ entry through TRPC5 might induce dendritic and axonal remodeling, which could lead to cell death, as our findings clearly indicate that TRPC5 is an important regulator of neurite remodeling.
\end{abstract}

\section{Introduction}

The retina is an important sensory organ that converts visual information (light stimuli) into electrical signals and transmits them to the brain through the optic nerve. Thus, the retina is an ideal model for studying neural development and

Supplementary information The online version of this article (https:// doi.org/10.1038/s41374-019-0347-1) contains supplementary material, which is available to authorized users.

Koji Shibasaki

kshibasaki@sun.ac.jp

1 Department of Molecular and Cellular Neurobiology, Gunma University Graduate School of Medicine, Maebashi 371-8511, Japan

2 Department of Ophthalmology, Gunma University Graduate School of Medicine, Maebashi 371-8511, Japan regeneration. The retina is a laminar structure composed of seven cell types (six types of neurons and one type of glial cell), and these cells exist in three cell layers: the rod and cone photoreceptors in the outer nuclear layer, the horizontal cells, amacrine cells (ACs), bipolar cells and Müller glial cells in the inner nuclear layer (INL), and retinal ganglion cells (RGCs) in the ganglion cell layer (GCL) [1]. During embryonic stages, RGCs are the first neuronal cell type to form, and cone photoreceptors, horizontal cells, and ACs form at about the same time following RGC specification. In contrast, rod photoreceptors, bipolar cells, and Müller glial cells are generated during postnatal stages $[1,2]$. Among these cell types, RGCs are the specific neurons that extend long axons through the optic nerve and project to the brain. This unique feature of RGCs is strictly distinct from other retinal cell types; thus, RGCs have been widely used as a model to study axonal growth and regeneration.

The developmental processes of cell proliferation, cell migration, axonal outgrowth, axon pathfinding, and synapse 
formation are necessary for neural circuit formation during development [3-6]. During this period, the growth cone at the tip of the growing axon receives information from the extracellular environment; this includes secreted factors that guide axons toward the target site. Growth factors, such as NGF, regulate axonal outgrowth, pathfinding, or movement via changes in intracellular calcium/cyclic nucleotide (cAMP and cGMP) levels [7]. In particular, intracellular $\mathrm{Ca}^{2+}$ influx drives intracellular signaling cascades that regulate axonal outgrowth and growth cone motility [8,9]. The molecular identity of the ion channels that mediate intracellular $\mathrm{Ca}^{2+}$ in developing neurons is largely unknown, although transient receptor potential (TRP) channels are good candidates because most TRP channels are permeable to $\mathrm{Ca}^{2+}[10]$.

TRP channels are a large group of ion channels that comprise six subfamilies (TRPC, TRPV, TRPM, TRPA, TRPML, and TRPP), and 28 different ones have been identified in mammals $[11,12]$. TRP channels serve as key molecules for transmitting sensory information such as chemical stimulation, thermal stimulation, and mechanical stimulation [13-16]. Among the TRP channels, the TRP canonical (TRPC) subfamily was identified during a search for homologues of the Drosophila transient receptor potential gene (trp) [17]. In mammals, seven members of the TRPC subfamily have been identified (TRPC1-TRPC7) and function as $\mathrm{Ca}^{2+}$ permeable nonselective cation channels by forming homo- or heterotetramers $[11,18]$. The TRPC subfamily is also activated by receptor stimulation, depletion of intracellular $\mathrm{Ca}^{2+}$ stores, and interactions with other proteins.

TRPC5 was originally cloned and identified as a channel that is activated upon depletion of intracellular $\mathrm{Ca}^{2+}$ stores [19], as well as by various stimuli such as the Gq-PLC pathway, NO, mechanical stimulation (membrane stretch), and cold temperatures $\left(<25-37^{\circ} \mathrm{C}\right)$ [20-25]. TRPC5 is abundantly expressed in the embryonic rodent brain $[26,27]$. Notably, it has been reported that $\mathrm{Ca}^{2+}$ influx via TRPC5 activation in the growth cone suppresses axonal outgrowth in rat hippocampal neurons [28]. Therefore, we hypothesized that TRPC5 might be expressed in the developing retina, where the increase in $\mathrm{Ca}^{2+}$ influx through TRPC5 activation may play similar physiological roles as in hippocampal neurons during development.

In the chick, the expression of TRPC5 in the retina is restricted to ACs and Müller glial cells [29]. Consistent with this finding, in the mouse retina TRPC5 is expressed in the IPL and INL in what are thought to be ACs and Mueller glia $[30,31]$. Chick TRPC5 is also expressed in cell bodies of the GCL, and these cells are presumed to be displaced ACs based on their characteristic cell morphology [29]. Moreover, it has been reported that TRPC5 expression in the chick retina is required for NO-dependent increases in dendritic $\mathrm{Ca}^{2+}$ and GABA release from ACs [29]. However, given that this previous analysis in chick focused specifically on ACs, it is possible that it failed to identify TRPC5 expression in the RGCs, because RGCs and ACs coexist in the GCL. Furthermore, the expression profile and function of TRPC5 during development remains largely unknown. In this study, we examined whether TRPC5 is expressed in RGCs and contributes to the regulation of neural circuit formation during development.

\section{Materials and methods}

\section{Animals}

All animal experiments were performed according to the guidelines of the Gunma University Animal Care and Experimentation Committee. C57BL/6 mice were purchased from SLC (Japan). Embryos were defined as E0.5 when a copulation plug was observed.

\section{BrdU labeling}

For bromodeoxyuridine (BrdU, Sigma Aldrich) labeling experiments, pregnant females were injected intraperitoneally with $10 \mathrm{mM} \mathrm{BrdU}(20 \mu \mathrm{L} / \mathrm{g}$ body weight $) 1 \mathrm{~h}$ before they were sacrificed.

\section{Immunohistochemistry and in situ hybridization}

For immunohistochemistry and in situ hybridization, embryos (E12.5-P0) and eye cups (P3-adult) were fixed in $4 \%$ paraformaldehyde (PFA)/PBS at $4{ }^{\circ} \mathrm{C}$ overnight. The samples were infused with $30 \%$ sucrose at $4{ }^{\circ} \mathrm{C}$ overnight and frozen in OCT compound (Tissue-Tek). The samples were cryosectioned at $16-20 \mu \mathrm{m}$. In situ hybridization was performed as previously described [32]. Digoxigenin-labeled antisense probes were used for this study. After linearizing the plasmid (antisense: NheI, sense: NotI), digoxigeninlabeled antisense probe and sense probe were synthesized by RNA polymerase (antisense: T3 RNA polymerase, sense: T7 RNA polymerase). Detection of mRNA on retinal cryosections $(20 \mu \mathrm{m})$ was performed by nitro blue tetrazolium chloride/5-bromo-4-chloro-3-indolyl phosphate using an alkaline phosphatase conjugated anti-digoxigenin antibody (Roche). For immunohistochemistry, retinal sections were washed three times with PBS containing 0.3\% Triton X-100 (PBS-T) and blocked in 3\% bovine serum albumin (BSA) in PBS-T at room temperature for $1 \mathrm{~h}$. The sections were then incubated with primary antibodies at $4{ }^{\circ} \mathrm{C}$ overnight. The following antibodies were used: rabbit anti-TRPC5 (1:250, Sigma Aldrich), mouse anti-Brn3a (1:100, Santa Cruz), mouse anti-calretinin (1:1000, Millipore), sheep anti-Chx10 (1:200, Exalpha), mouse anti-calbindin D28K (1:2000, 
Swant), mouse anti-glutamine synthetase (GS; 1:500, Millipore), mouse anti-Ki67 (1:500, BD Pharmingen), and rat anti-BrdU (1:1000, Abcam), rabbit anti-IgG (1:5000, GE Healthcare Life Sciences). After washing with PBS-T, slides were incubated in secondary antibodies for $1 \mathrm{~h}$ at room temperature. The following secondary antibodies were used: goat anti-rabbit IgG (Alexa Fluor 488, 1:500, Thermo Fisher Scientific), donkey anti-mouse IgG (Alexa Fluor 546, 1:500, Thermo Fisher Scientific), donkey anti-sheep IgG (Alexa Fluor 568, 1:500, Thermo Fisher Scientific), and goat anti-rat Alexa Flour 546 IgG (1:500, Thermo Fisher Scientific). Hoechst 33342 (Sigma Aldrich) was used for staining nuclei. All fluorescence images were captured with a fluorescence microscope (BZ-9000, Keyence) or a confocal microscope (LSM-880, Zeiss).

\section{Transfection of cDNAs and immunocytochemistry}

HEK293 cells cultured 1 day were transfected with $1 \mu \mathrm{g} / \mathrm{mL}$ of mouse TRPC5/pCX with $0.1 \mu \mathrm{g} / \mathrm{mL}$ EGFP/pCX or $1 \mu \mathrm{g} /$ $\mathrm{mL}$ EGFP/pCX alone cDNAs using Lipofectamine2000 Reagent (Invitrogen). The cells were fixed in 4\% PFA/PBS for $10 \mathrm{~min}$. Those were washed three times with PBS-T and blocked in 3\% BSA in PBS-T at room temperature for $1 \mathrm{~h}$. The cells were then incubated with primary antibodies at $4{ }^{\circ} \mathrm{C}$ overnight. The following antibodies were used: rabbit anti-TRPC5 (1:250, Sigma Aldrich) and rat anti-GFP (1:1000, Nacalai Tesque). After washing with PBS-T, the following secondary antibodies were used: donkey anti-rabbit Alexa Fluor 546 IgG (1:500, Thermo Fisher Scientific) and goat anti-rat Alexa Flour 488 IgG (1:500, Thermo Fisher Scientific).

\section{Culture of dissociated embryonic retinal cells}

Embryonic retinal cell cultures were established using E17.5 embryos. Eyes were enucleated, and the retinas were carefully isolated and placed in cold Neurobasal medium (Invitrogen) containing 2\% B27 supplement (Invitrogen), $0.25 \%$ GlutaMax (Gibco), 10\% fetal bovine serum (FBS; Thermo Fisher Scientific), and $1 \%$ penicillin-streptomycin (Gibco). To digest the extracellular matrix, eye cups were incubated in Neurobasal medium containing papain (7 U/ $\mathrm{mL}$, Worthington) for $1 \mathrm{~h}$ at room temperature. After digestion, retinas were rinsed in cold Neurobasal medium, and cut into $500 \mu \mathrm{m}$ pieces. Cells were dissociated using mechanical trituration, and were plated on poly-L-lysine $(100 \mu \mathrm{g} / \mathrm{mL})$ and laminin $(20 \mu \mathrm{g} / \mathrm{mL})$ coated coverslips (14 $\mathrm{mm}$ round; Matsunami). The following antagonists were diluted in culture medium to the specified final concentrations: $10 \mu \mathrm{M}$ clemizole (Tocris) or $75 \mu \mathrm{M}$ tranilast (Sigma Aldrich), antagonists of TRPC5 and TRPV2, respectively. Four days after plating on coverslips, dissociated embryonic retinal cells were fixed with $4 \%$ PFA/PBS for 20 min. Cells were washed with PBS-T and blocked in 3\% BSA in PBS-T, then were incubated with the following primary antibodies: rabbit anti-Neurofilament $\mathrm{M}$ (NF-M; 1:500, Millipore) and rat anti-GFP (1:1000, Nacalai Tesque) for $2 \mathrm{~h}$ at room temperature. After washing with PBS-T, the following secondary antibodies were used: goat anti-rabbit Alexa Fluor 488 IgG (1:500, Thermo Fisher Scientific), donkey anti-rabbit Alexa Fluor 546 IgG (1:500, Thermo Fisher Scientific), and goat anti-rat Alexa Flour 488 IgG (1:500, Thermo Fisher Scientific). The length of retinal ganglion cell axons was measured using Image $\mathbf{J}$ software (http://imagej.nih.gov/ij/; provided in the public domain by the National Institutes of Health).

\section{$\mathrm{Ca}^{2+}$ imaging}

Fluo-4 fluorescence was measured in dissociated embryonic RGCs using standard bath solution containing $140 \mathrm{mM}$ $\mathrm{NaCl}, 5 \mathrm{mM} \mathrm{KCl}, 2 \mathrm{mM} \mathrm{MgCl}_{2}, 2 \mathrm{mM} \mathrm{CaCl}, 10 \mathrm{mM}$ HEPES, and $10 \mathrm{mM}$ glucose at $\mathrm{pH} 7.4$ (adjusted with $\mathrm{NaOH}$ ). Fluo-4 AM was diluted to $2 \mu \mathrm{M}$ in a standard bath solution with $0.1 \%$ pluronic F-127 (Life Technologies) and loaded into the cells by incubation for $30 \mathrm{~min}$ at $37^{\circ} \mathrm{C}$ with $5 \% \mathrm{CO}_{2}$. After incubation, excess Fluo-4 AM dye was washed out with three rinses of the standard solution. Fluorescence images of Fluo-4 AM were captured at $5 \mathrm{~s}$ intervals for $150 \mathrm{~s}$ with an upright fluorescence microscope (BX51WI, Olympus) equipped with a CMOS camera (Neo, Andor).

\section{Plasmid construction}

The full-length mouse TRPC5 in the pCI Neo plasmid was cut out by NheI and NotI digestion, and the fragment was treated with T4 DNA polymerase to generate blunt ends. The TRPC5 fragment was subcloned into pCX (in which the NheI site was blunt ended).

\section{In vitro electroporation}

Electroporation was performed as previously described [32]. TRPC5/pCX plasmid solutions (final concentration, $5 \mu \mathrm{g} / 100 \mu \mathrm{L}$ ) in PBS containing EGFP/pCX plasmid DNA were transferred to the electroporation chamber with the embryonic eye cups (E17.5). Five square pulses $(33 \mathrm{mV})$ of $50 \mathrm{~ms}$ duration with $950 \mathrm{~ms}$ intervals were applied by a pulse generator, ECM830 (BTX).

\section{Data analysis}

Data are expressed as the means \pm SEM. Significance of the observed changes was assessed using Student's unpaired 
$t$ test and ANOVA. A difference of $p<0.01$ was considered statistically significant.

\section{Results}

\section{TRPC5 expression is restricted to the GCL and INL in the developing mouse retina}

We first examined the expression patterns of TRPC5 during development through adulthood (E12.5-adult) by in situ hybridization in mouse retinal tissue sections. As the negative controls, we performed in situ hybridization with sense probe to confirm the specificity of antisense probe. The signal was not detected with sense probe (Supplementary Fig. 1A-D). Very weak TRPC5 mRNA signal was detected in the GCL at E12.5 (Fig. 1a, arrowheads), we expected that this weak signal might be negative. To further confirm whether the weak signal was positive or negative, we checked the protein expression. We failed to detect the protein signals (Supplementary Fig. 1E). Therefore, we concluded that TRPC5 was not expressed at E12.5 (Fig. 1a and Supplementary Fig. 1E). At E14.5, clear TRPC5 mRNA signals were detected in the GCL (Fig. 1b). Approximately $70 \%$ of the cells were TRPC5-positive in the GCL (Fig. 1b, arrowheads). Compared with E14.5, the number of TRPC5positive cells in the GCL was not changed at E16.5 (Fig. 1c). At P0, TRPC5-positive cells comprised most of the cells in the GCL (Fig. 1d). Moreover, at postnatal

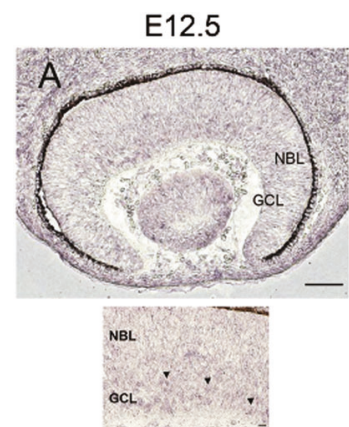

E16.5

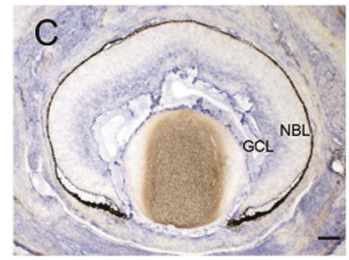

Fig. 1 Expression pattern of TRPC5 mRNA during prenatal stages. a-d The expression pattern of TRPC $5 \mathrm{mRNA}$ at prenatal stages (E12.5, E14.5, E16.5, and P0) by in situ hybridization. Highmagnification images of the GCL were added in $\mathbf{a}$ and $\mathbf{b}$. The arrowheads indicate TRPC5-positive mRNA in the GCL. Scale bar: $100 \mu \mathrm{m}(\mathbf{a}-\mathbf{d})$. NBL neuroblast layer, GCL ganglion cell layer. stages, in addition to the GCL, TRPC5 mRNA expression was also detected in the INL at P3 (Fig. 2a). TRPC5 mRNA expression in the GCL and INL continued from P3 to P21, and the TRPC5 mRNA signal was stronger depending on the maturity of the cells in the INL (Fig. 2a-d). In the adult retina, the level of TRPC5 mRNA detected in the GCL and INL was stronger than at P21. It was previously reported that TRPC5 is required for the NO-dependent increase in dendritic $\mathrm{Ca}^{2+}$ and GABA release from ACs in the chicken retina [29]. The level of TRPC5 expression in the INL of the adult retina is likely stronger than at P21 because it is predicted that the increased expression regulates neurotransmitter release from the ACs through TRPC5 activation.

We next examined TRPC5 protein expression in the adult retina (Fig. 3). We performed an immunoblotting or an immunostaining experiment to confirm the specificity of the TRPC5 antibody. We prepared HEK293 cells expressing EGFP alone or mouse TRPC5 + EGFP. Unfortunately, the TRPC5 antibody was not suitable for immunoblotting experiment, since we failed to find significant differences about the band patterns between EGFP alone and TRPC5 + EGFP (data not shown). By immunostaining detection, TRPC5 protein was not detected in EGFP-negative cell (Fig. 3a, arrow). TRPC5 protein was specifically observed in the EGFP-positive cells (Fig. 3a). The TRPC5 is localized in the endoplasmic reticulum and the endosome, also localized in plasma membrane (Fig. 3a, arrowheads). These results clearly indicated that the TRPC5 antibody specifically recognized the TRPC5 protein by immunostaining (Fig. 3a). We also compared the results by TRPC5 antisense probe and TRPC5 antibody in adult retina. TRPC5 mRNA was detected in the GCL and the INL by the antisense probe (Fig. 3b, left), but TRPC5 mRNA signal was not detected

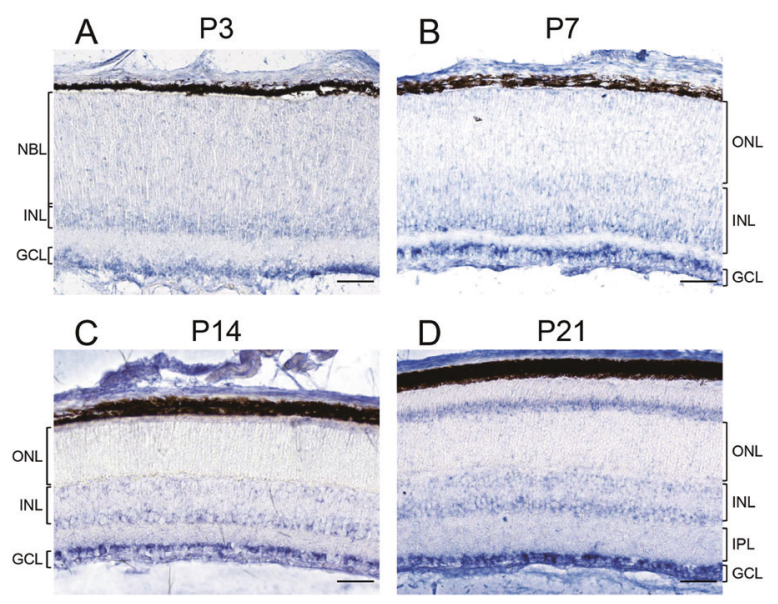

Fig. 2 Expression pattern of TRPC5 mRNA during postnatal stages. a-d The expression pattern of TRPC 5 mRNA during postnatal stages (P3, P7, P14, and P21) by in situ hybridization. Scale bar: $50 \mu \mathrm{m}$ (a-d). NBL neuroblast layer, GCL ganglion cell layer, IPL inner plexiform layer, INL inner nuclear layer, ONL outer nuclear layer. 
Fig. 3 Comparison of TRPC5 mRNA and protein expression in the adult retina. a HEK293 cells expressing mouse TRPC5 + EGFP were stained by anti-GFP (green) and antiTRPC5 (red) antibodies. The nuclei were visualized by Hoechst (cyan). The arrow indicates EGFP- and TRPC5negative cell. The arrowheads indicate TRPC5 protein localized in the plasma membrane. b The expression pattern of TRPC 5 mRNA by antisense probe (left) and sense probe (right) in the adult retina. c Immunostaining for TRPC5 (green) and Hoechst (cyan) in the adult retina.

d Immunostaining by anti-rabbit IgG antibody (green) and Hoechst (cyan) in the adult retina. Scale bar: $5 \mu \mathrm{m}(\mathbf{a})$; $20 \mu \mathrm{m}$ (b-d). GCL ganglion cell layer, IPL inner plexiform layer, INL inner nuclear layer, ONL outer nuclear layer.
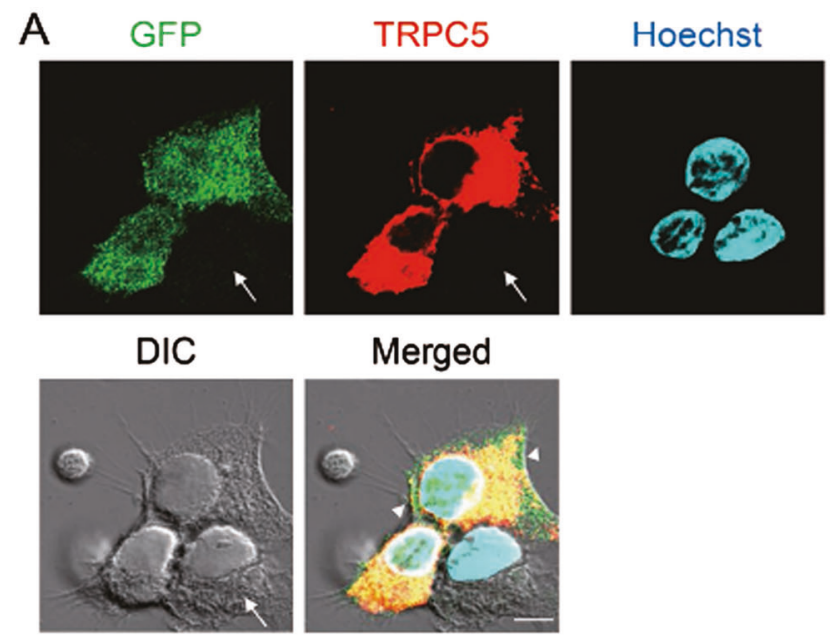

Merged

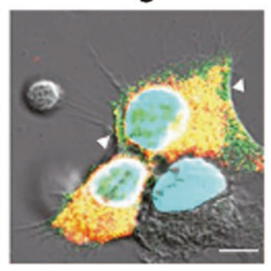

B
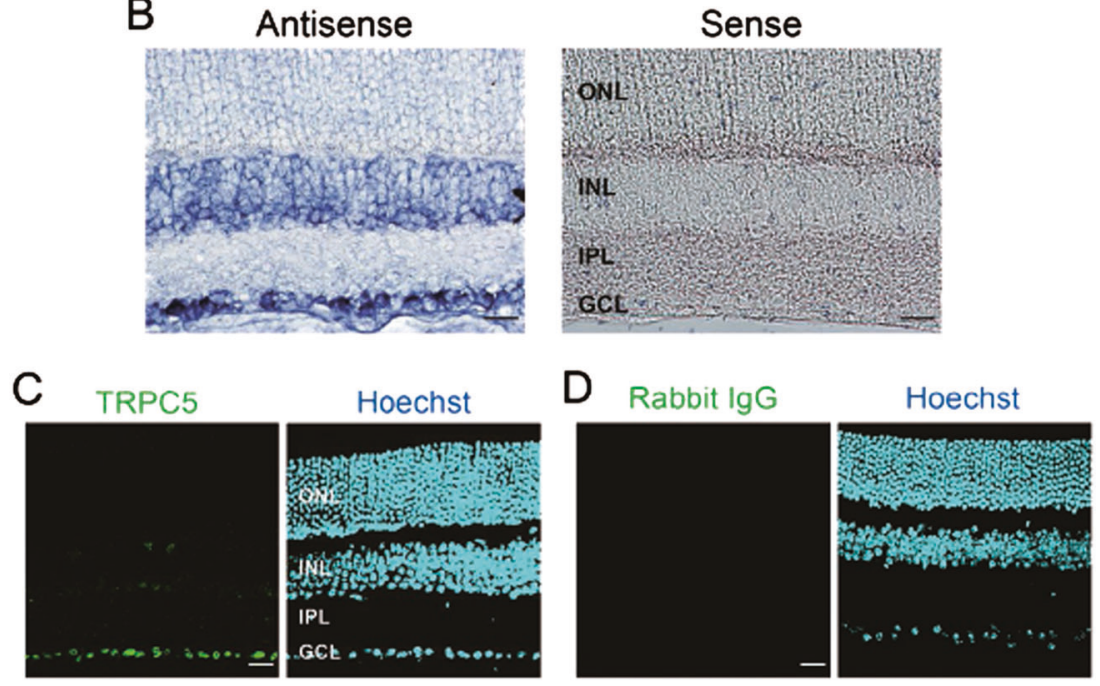

by the sense probe (Fig. 3b, right). Consistent with the expression pattern of TRPC 5 mRNA (Fig. 3b, left), TRPC5 protein was detected in the GCL and the INL (Fig. 3c). But, the signal was not detected by anti-rabbit IgG by immunostaining (Fig. 3d). These results indicate that our TRPC5 antibody and TRPC5 antisense probe are able to specifically detect the TRPC5. Combined, these results indicate that TRPC5 is strongly expressed in the GCL and INL during mouse retinal development.

\section{TRPC5 is strongly expressed in developing RGCs and ACs}

The early-born neurons such as RGCs, ACs, horizontal cells, and cone photoreceptors are generated during embryonic stages. For example, RGC generation begins around E11 and continues until P1 [33]. In order to determine which cell types express TRPC5 protein in the GCL at embryonic stages, we performed double immunostaining for TRPC5 and RGC marker (Brn3a) or AC marker (calretinin; Fig. 4). First, we examined whether TRPC5 is expressed in Brn3a-positive
RGCs. Brn3a expression was observed in the GCL from E14.5 to P0 as reported [34], and TRPC5 signals were clearly colocalized with Brn3a in the GCL (Fig. 4a-d, inset). In the P0 retina, TRPC5 expression was also observed in the INL (Fig. 4d). The number of TRPC5 and Brn3a-positive cells increased depending on the developmental stage until E18.5. We next compared the retinal expression of TRPC5 and calretinin. Calretinin was expressed in the GCL at E14.5 and E18.5 (Fig. 4e, f). Consistent with the Brn3a results (Fig. 4a, c), TRPC5 expression was colocalized with calretinin in the GCL at E14.5 and E18.5 (Fig. 4e, f). The number of TRPC5 and calretinin-positive cells was greater at E18.5 than at E14.5, similar to Brn3a (Fig. 4a, c). These results indicate that TRPC5 is expressed in the RGCs and ACs of the GCL at prenatal stages.

\section{TRPC5 expression begins in postmitotic cells at embryonic stages}

Since the expression of TRPC5 at E12.5 was undetectable by in situ hybridization and immunostaining (Fig. 1a and 
Fig. 4 Comparison of TRPC5 expression with markers of RGCs or ACs at prenatal stages. a-d Immunostaining for TRPC5 (green) with an RGC marker, Brn3a (red), and Hoechst (cyan) from E14.5 to P0. e, f Immunostaining for TRPC5 (green) with an AC marker, calretinin (red), and Hoechst (cyan) at E14.5 and E18.5. The white boxed regions in the merged figures are highmagnification views of the same images; the insets in a-d show TRPC5 and Brn3a-positive cells in the GCL; insets in $\mathbf{e}, \mathbf{f}$ show TRPC5 and calretinin-positive cells in the GCL. Scale bar: $20 \mu \mathrm{m}$. NBL neuroblast layer, INL inner nuclear layer, GCL ganglion cell layer.
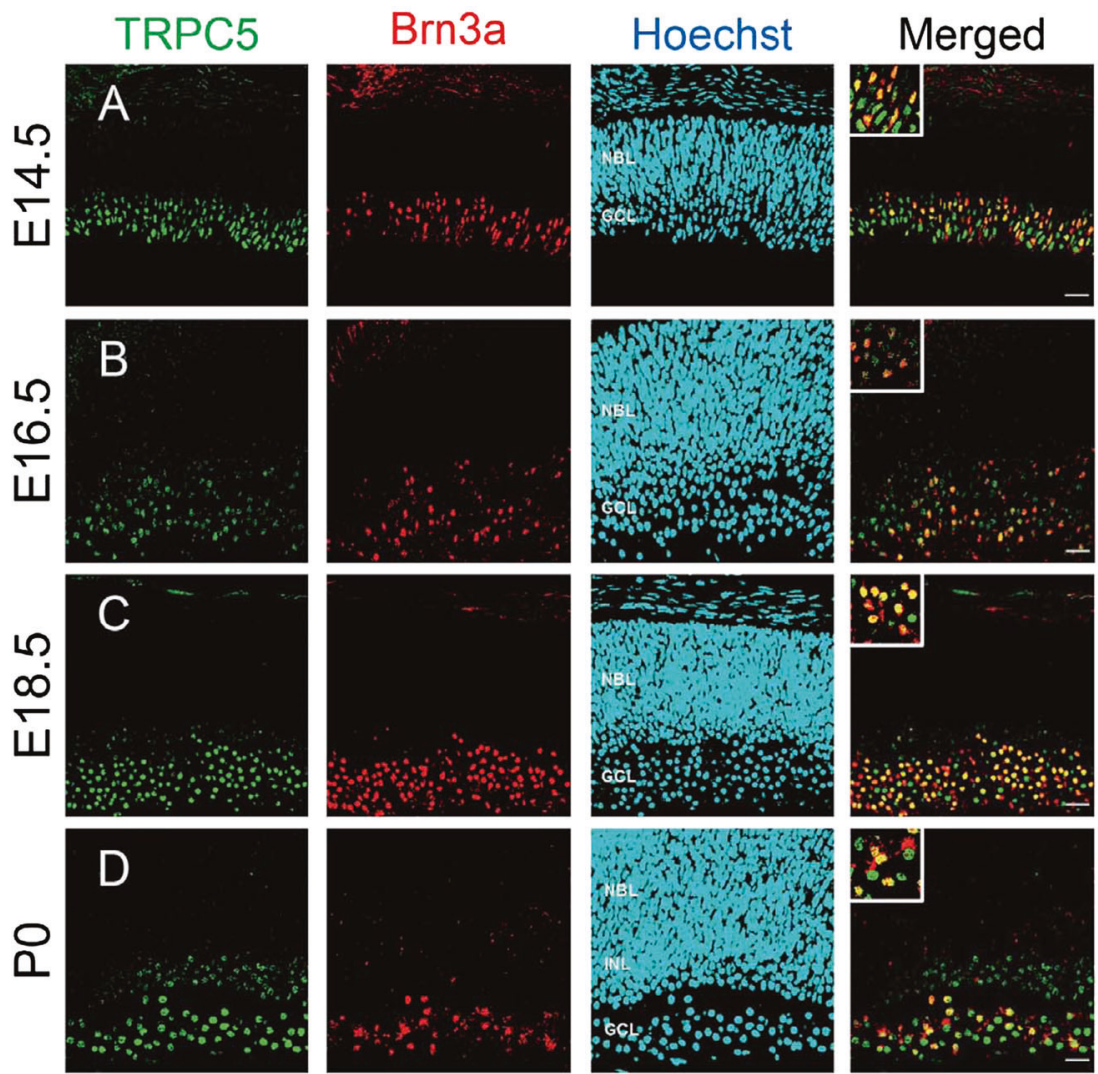

TRPC5

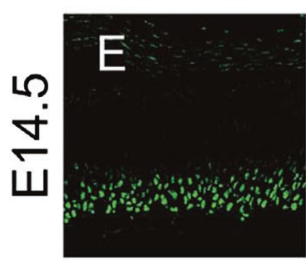

calretinin

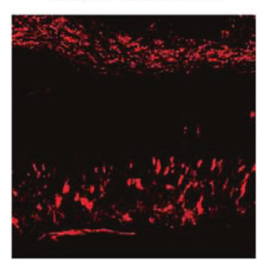

Hoechst

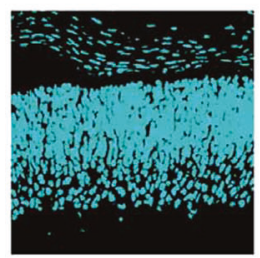

Marge
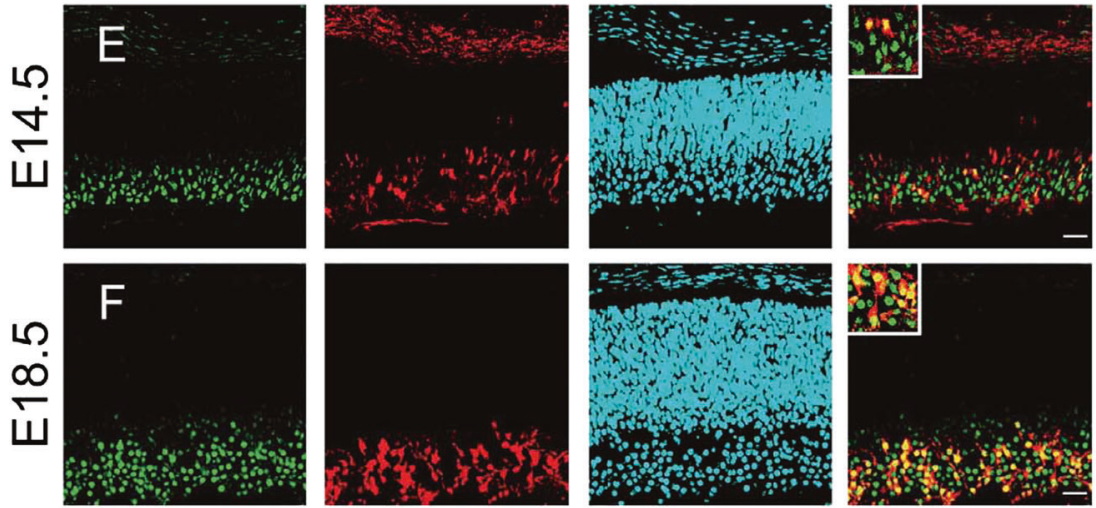

Supplementary Fig. 1E). Thus, we concluded that TRPC5 expression begins at approximately E14.5 by in situ hybridization and immunostaining (Figs. $1 \mathrm{~b}$ and 4a). Embryonic-specific events such as cell proliferation, apoptosis, cell migration, and neurite outgrowth occur in developing embryonic stage cells and are accompanied by TRPC5 expression. This suggests that TRPC5 may be expressed in proliferating precursor cells and is involved in cell proliferation. Thus, we performed double immunostaining with a cell proliferation marker, Ki67, to confirm whether TRPC5 is involved in cell proliferation. We observed that most cells of the neuroblast layer were proliferative (Ki67-positive cells). However, not all TRPC5-positive cells were coexpressed with Ki67 in the GCL at E14.5 and E18.5, and the Ki67-labeling experiment suggests that TRPC5 is only found in postmitotic cells at E14.5 and at E18.5 (Fig. 5a, arrowheads and b). We also performed a BrdU-labeling experiment at E18.5. BrdU was injected into pregnant dams at E18.5 and animals were sacrificed $1 \mathrm{~h}$ later. The expression of TRPC5 was not observed in S-phase proliferating cells (Fig. 5c). These results indicate that TRPC5 is expressed in postmitotic cells of the GCL beginning at E14.5, and suggest that TRPC5 is not related to cell proliferation. 
Fig. 5 Comparison of TRPC5 expression with a marker of proliferating cells. $\mathbf{a}, \mathbf{b}$ Immunostaining for TRPC5 (green) with the proliferating cell marker Ki67 (red) and Hoechst (cyan) at E14.5 and E18.5. The arrowheads represent TRPC5-positive and Ki67negative cells in the GCL. c Immunostaining for TRPC5 (green) with BrdU (red) and Hoechst (cyan) at E18.5. Scale bar: $20 \mu \mathrm{m}(\mathbf{a}-\mathbf{c}) . \mathbf{d}$ The figure at left shows representative traces of $\left[\mathrm{Ca}^{2+}\right] \mathrm{i}$ changes in cultured RGCs. $\left[\mathrm{Ca}^{2+}\right]$ i changes were measured by Fluo- 4 AM, and data were quantified as $\Delta \mathrm{F} / \mathrm{F} 0$. Fetal bovine serum (FBS, 10\%) was applied at $30 \mathrm{~s}$. At $90 \mathrm{~s}$, the TRPC5 antagonist clemizole $(10 \mu \mathrm{M})$ was added. The figure at right is an enlarged graph of the red boxed region in the left figure, and shows the changes in $\left[\mathrm{Ca}^{2+}\right] \mathrm{i}$ from 80 to $130 \mathrm{~s}$.
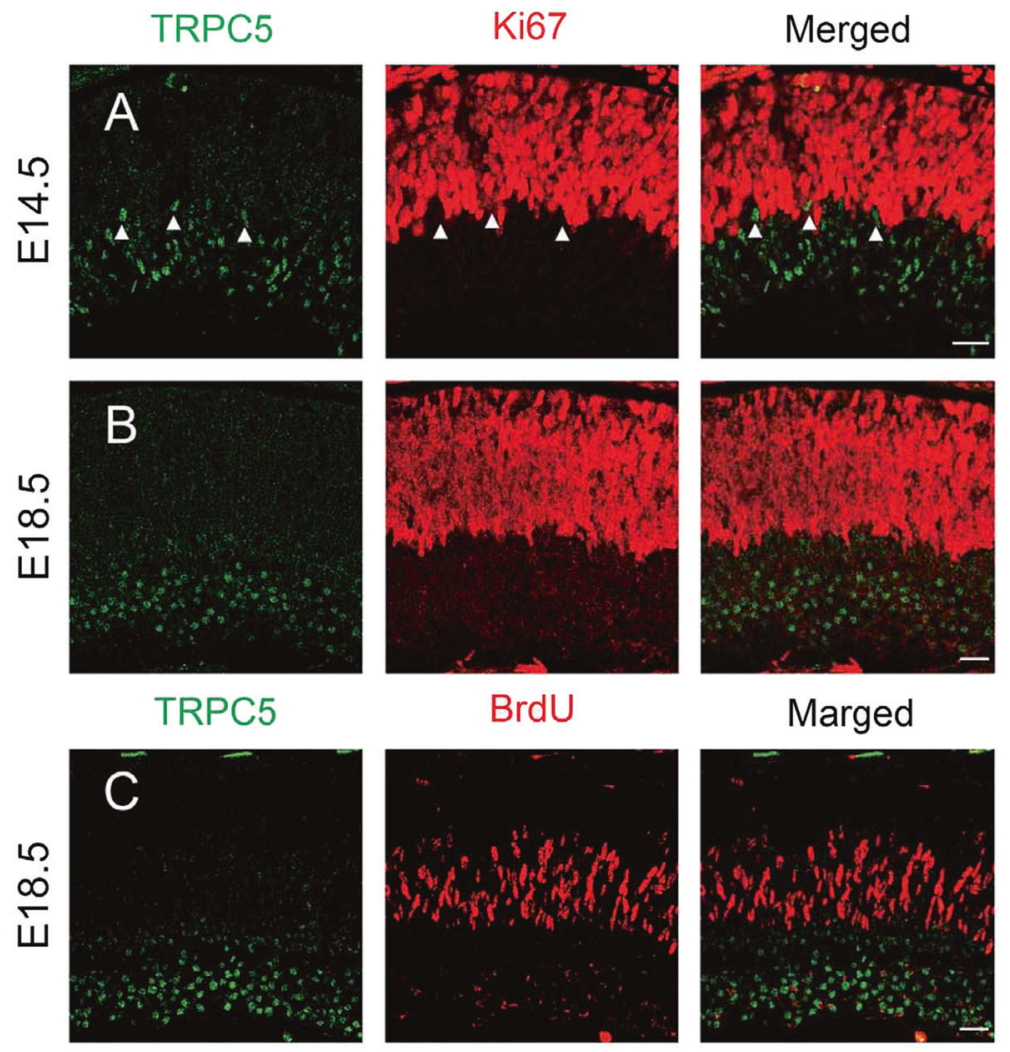

BrdU
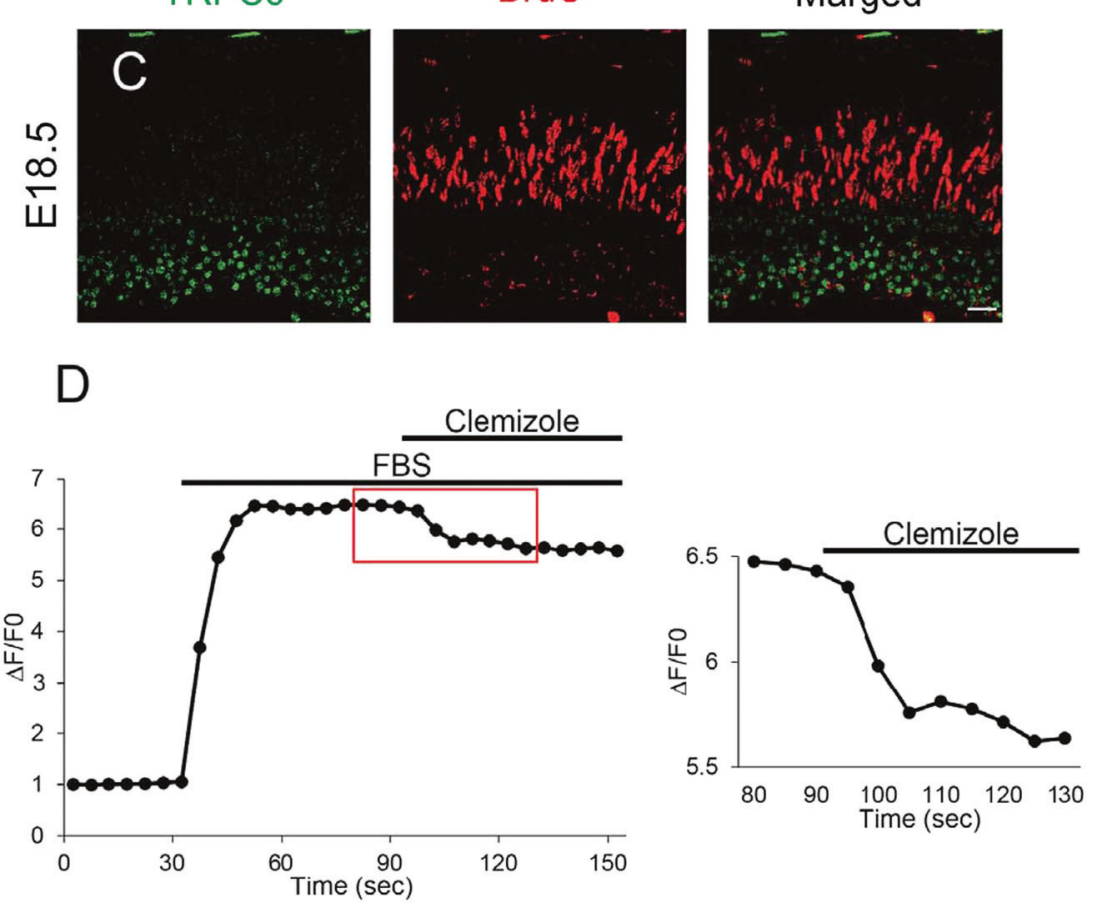

\section{TRPC5 is functionally expressed in developing RGCs}

To confirm the functional expression of TRPC5 in RGCs, we performed $\mathrm{Ca}^{2+}$ imaging experiments using Fluo-4 AM dye (Fig. 5d). Dissociated retinal cells were prepared from E17.5 mouse embryos and cultured for 4 days. We then measured changes in $\left[\mathrm{Ca}^{2+}\right]_{i}$ in RGCs after application of $10 \%$ FBS to confirm if TRPC5 is functionally expressed in RGCs. Application of 10\% FBS evoked an acute and large increase in $\left[\mathrm{Ca}^{2+}\right]_{\mathrm{i}}$ in RGCs (Fig. 5d). This FBS-evoked $\left[\mathrm{Ca}^{2+}\right]_{\mathrm{i}}$ increase was reduced by the application of $10 \mu \mathrm{M}$ clemizole, a TRPC5 specific antagonist [35] (Fig. 5d, the red boxed region is shown as a higher magnification graph at far right). These results indicate that TRPC5 is functionally expressed in developing RGCs.

\section{TRPC5 is expressed in RGCs, ACs, and Müller glial cells at postnatal stages}

To examine the developmental changes in TRPC5 expression in postnatal RGCs and ACs, we performed double immunostaining for TRPC5 with an RGC (Brn3a) or AC marker (calretinin; Figs. 6 and 7). Brn3a expression was observed in the GCL throughout postnatal stages, and most TRPC5 signal was colocalized with Brn3a in the GCL (Fig. 6a-d, inset), indicating that TRPC5 is strongly 
Fig. 6 Comparison of TRPC5 expression with an RGC marker at postnatal stages. a-d Immunostaining for TRPC5 (green) with the RGC marker Brn3a (red) and Hoechst (cyan) from P7 to adult. The white boxed regions in the merged figure are high-magnification views of the same images showing TRPC5 and Brn3apositive cells in the GCL. e High-magnification images of immunostaining for TRPC5 (green) with the RGC marker Brn3a (red) and Hoechst (cyan) in the adult. The image at right is further high-magnification image. The arrowheads indicate TRPC5 protein localized in the plasma membrane and the dendrites. Scale bar: $50 \mu \mathrm{m}$ $(\mathbf{a}-\mathbf{c}) ; 20 \mu \mathrm{m}(\mathbf{d}) ; 5 \mu \mathrm{m}(\mathbf{e})$. GCL ganglion cell layer, INL inner nuclear layer, ONL outer nuclear layer.
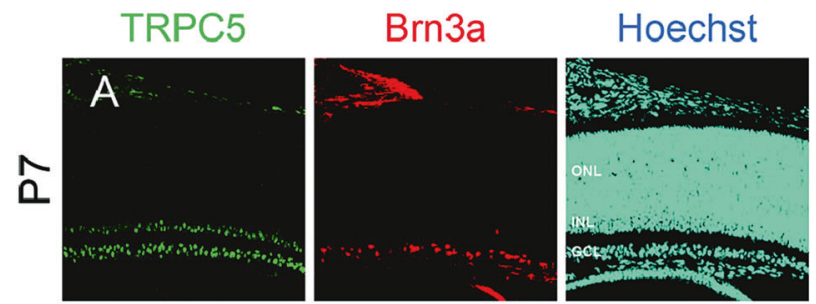

Merged
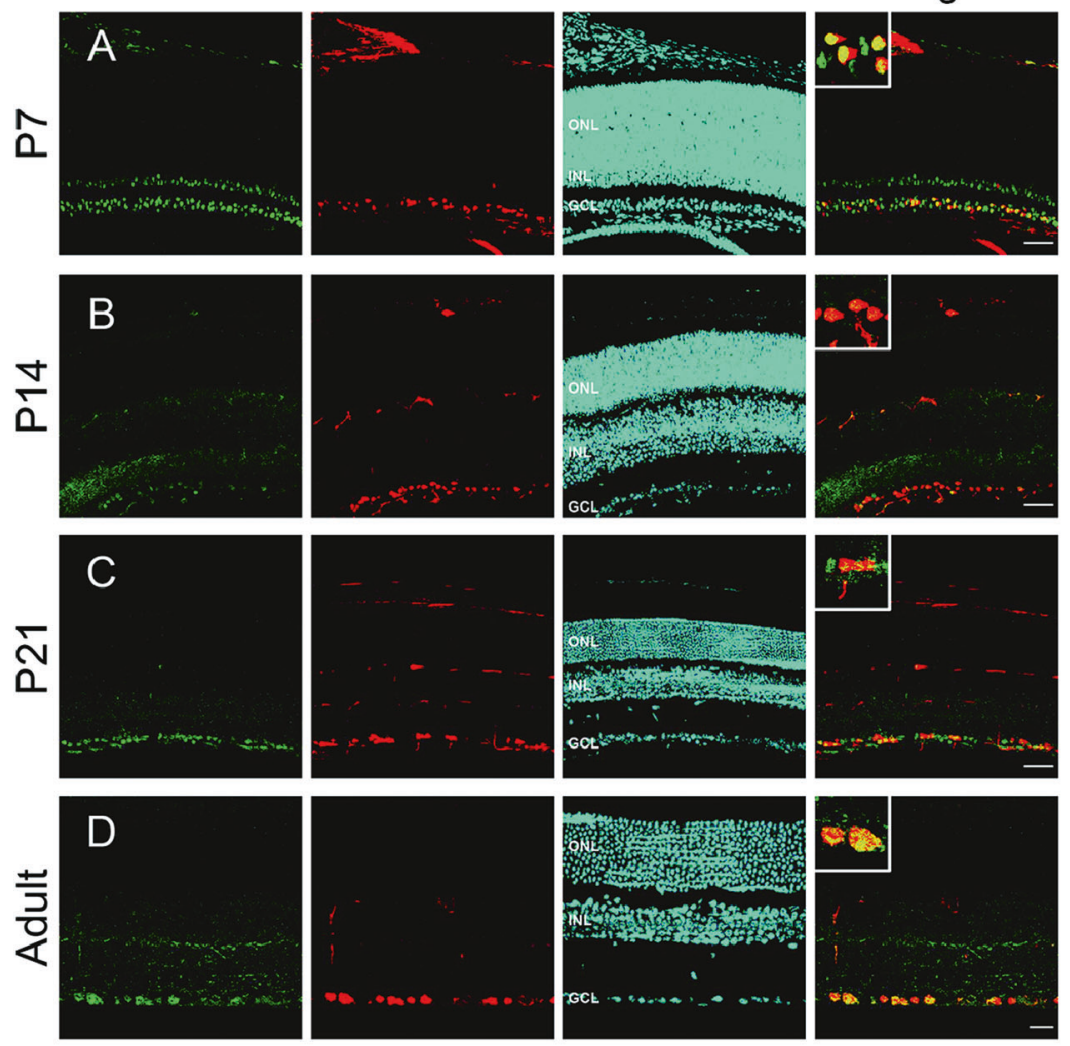

TRPC5

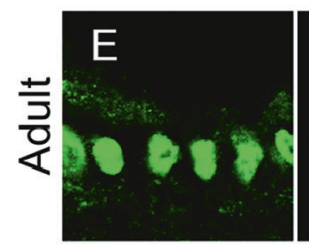

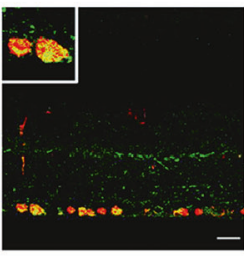

Merged

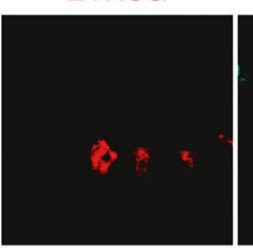

Hoechst

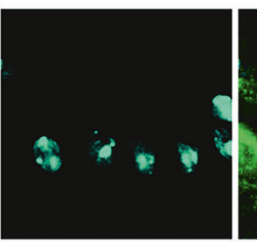

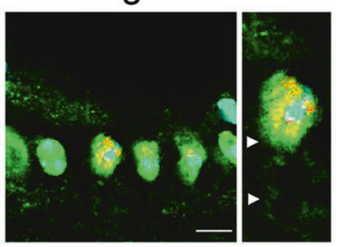

expressed by RGCs. The number of double-positive cells comprised $\sim 40 \%$ of cells in the GCL at P7 (Fig. 6a). In P21 and adult retinas, the number of double-positive cells increased to $\sim 70 \%$ of the total GCL cells (Fig. 6c, d). These results indicate that mature RGCs require TRPC5 for their physiological functions. Since the double immunostaining with Brn3a reduced the TRPC5 signals (may be due to the cross-reaction), we had to take the photographs by the highgain mode. These procedures unfortunately increased the background. Therefore, the TRPC5 image in Fig. 6d was different from that in Fig. 3c. To examine the subcellular localization of TRPC5 protein in the RGCs, we took the high-magnification image in adult (Fig. 6e). Notably, TRPC5 signals observed in outside of nuclei labeled by Brn3a and Hoechst (Fig. 6e). These results (Fig. 6e) and our $\mathrm{Ca}^{2+}$-imaging results (Fig. 5d) indicate that the TRPC5 protein was localized in both the plasma membrane and cytoplasm. As described above, our antibody did not detect any nuclear localization of TRPC5 in HEK293 cells
(Fig. 3a). In contrast to these results, we observed the colocalization of TRPC5 and Brn3a in RGCs (Fig. 6e). Thus, TRPC5 might be localized in RGC nuclei. Especially, we observed the dendritic localization of TRPC5 in the high-magnification images (Fig. 6e, arrowheads). Thus, we demonstrated that TRPC5 protein was localized in plasma membrane and cytoplasm in addition to the nuclei. Calretinin expression was observed in the GCL throughout postnatal stages, and its expression in the INL also began at P7 (Fig. 7a-d). Most TRPC5-positive cells were colocalized with calretinin in the GCL throughout postnatal stages (Fig. 7a-d, inset). The number of double-positive cells was $\sim 30 \%$ of the total cells in the GCL at P7 and P14 (Fig. 7a, b). In the P21 and adult retina, the number of double-positive cells increased to $\sim 70 \%$ of the GCL cells, and those were more localized to the GCL than the INL (Fig. 7c, d). The cell bodies of ACs located in the GCL and INL, and ACs located in the GCL are termed displaced ACs. Therefore, these results indicate that TRPC5 is mainly 
Fig. 7 Comparison of TRPC5 expression with an $\mathrm{AC}$ marker at postnatal stages. a-d Immunostaining for TRPC5 (green) with the AC marker calretinin (red) and Hoechst (cyan) from P7 to adult. The white boxed regions in the merged figures are highmagnification views of the same images showing TRPC5 and calretinin-positive cells in the GCL. Scale bar: $50 \mu \mathrm{m}(\mathbf{a}-\mathbf{c})$; $20 \mu \mathrm{m}(\mathbf{d})$.
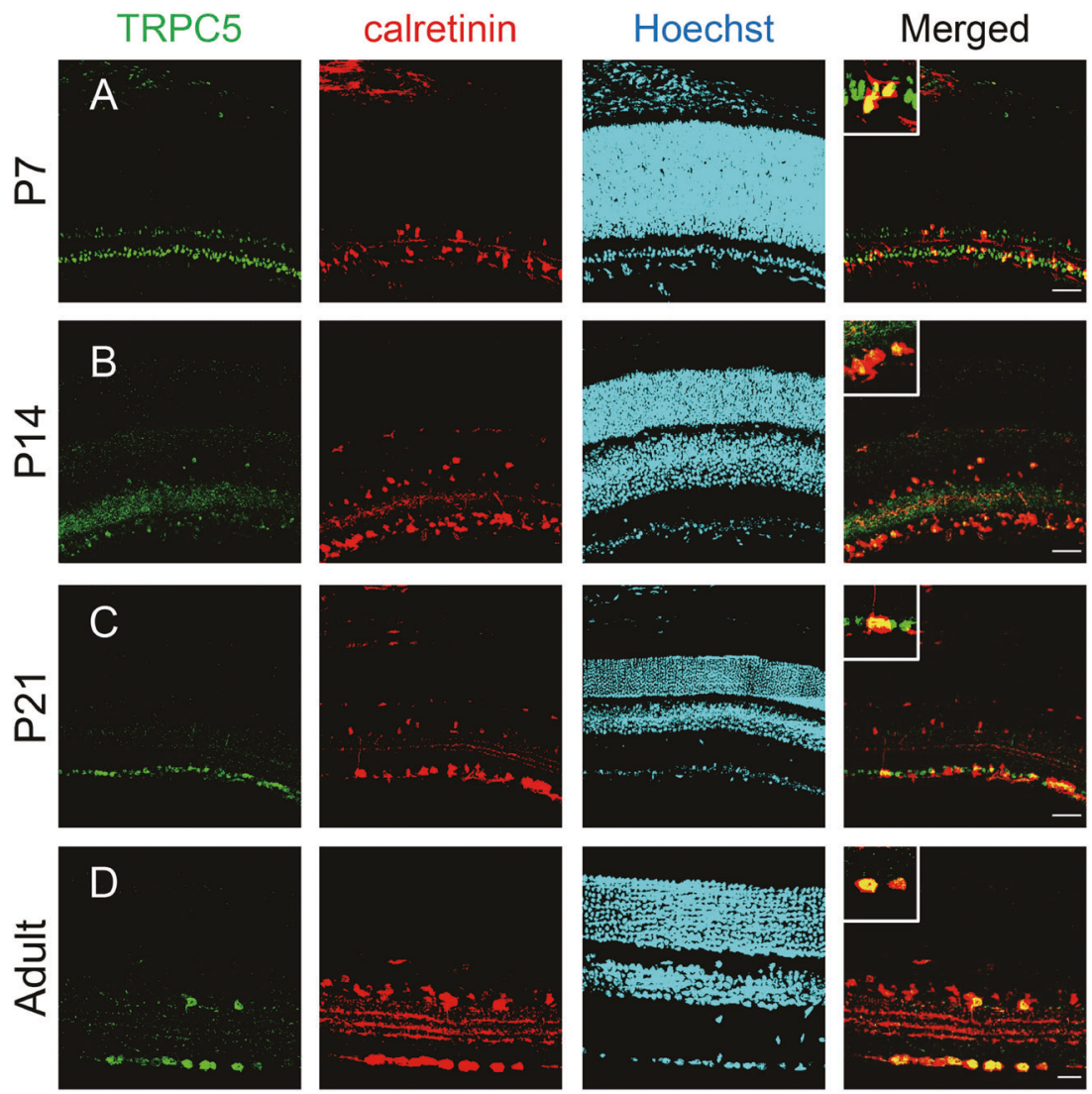

expressed in RGCs and displaced ACs in the GCL at postnatal stages.

The late-born cells, such as bipolar cells and Müller glial cells, are generated during early postnatal stages [33]. To further determine if TRPC5 protein is expressed in these late-born cells and horizontal cells, we performed double immunostaining for TRPC5 with a bipolar cell marker (Chx10), horizontal cell marker (calbindin), and Müller glial cell marker (glutamine synthetase, GS; Figs. 8 and 9). First, we examined the colocalization of TRPC5 and Chx 10. Chx10 expression was observed in the INL throughout the postnatal stages (Fig. 8a-d). The number of Chx10-positive cells peaked at P14 then was gradually reduced (Fig. 8a-d). At P7, TRPC5-positive cells were not colocalized with Chx10, and its expression pattern was observed throughout postnatal stages (Fig. 8a-d). These results indicate that TRPC5 is not expressed in bipolar cells during postnatal stages.

Next, we examined the colocalization of calbindin or GS in the adult retina. In adult retina, calbindin was detected in the INL, and TRPC5-positive cells did not colocalize with calbindin (Fig. 9a). Furthermore, GS-positive cell bodies were observed in the INL in the adult retina, and some TRPC5-positive cells in the INL overlapped with the GS signals which represent Müller glial cell bodies (Fig. 9b). Since the double immunostaining with GS reduced the
TRPC5 signals (may be due to cross-reaction), we had to take the photographs by the high-gain mode. These procedures unfortunately increased the background. Therefore, the TRPC5 image in Fig. 9b was different from that in Fig. 3c. Thus, these results suggest that TRPC5 is expressed in ACs and Müller glial cells in the adult retina, which is consistent with previous reports in the chicken retina [29]. Furthermore, for the first time we show that TRPC5 is expressed in the RGCs of the adult retina.

\section{TRPC5 activation inhibits axonal outgrowth in developing RGCs}

Since the peak timing of RGC axonal outgrowth occurs between E11 and P1 [33], and TRPC5 expression begins at E14.5 in RGCs (Fig. 4a), we hypothesized that TRPC5 activation might regulate RGC axonal outgrowth during retinal development similar to its function in hippocampal neurons [28]. To confirm this hypothesis, we examined whether TRPC5 activation regulates RGC axonal outgrowth. We prepared dissociated retinal cells from E17.5 mouse embryos and applied the TRPC5 antagonist clemizole $(10 \mu \mathrm{M})$ for 4 days. In addition, as a negative control, the TRPV2 antagonist tranilast [36] $(75 \mu \mathrm{M})$ was also applied. We performed immunostaining using NF-M to identify RGCs within the dissociated cells [37], and 
Fig. 8 Comparison of TRPC5 expression with a bipolar cell marker. a-d Immunostaining for TRPC5 (green) with the bipolar cell marker Chx10 (red) and Hoechst (cyan) from P7 to adult. Scale bar: $50 \mu \mathrm{m}(\mathbf{a}-\mathbf{c})$; $20 \mu \mathrm{m}(\mathbf{d})$.
Fig. 9 Comparison of TRPC5 expression with markers of horizontal cells or Müller glial cells in adults.

a Immunostaining for TRPC5 (green) with the horizontal cell marker calbindin (red) and Hoechst (cyan) in the adult. b Immunostaining for TRPC5 (green) with the Müller glial cell marker GS (red) and Hoechst (cyan) in the adult. Scale bar: $20 \mu \mathrm{m}$.
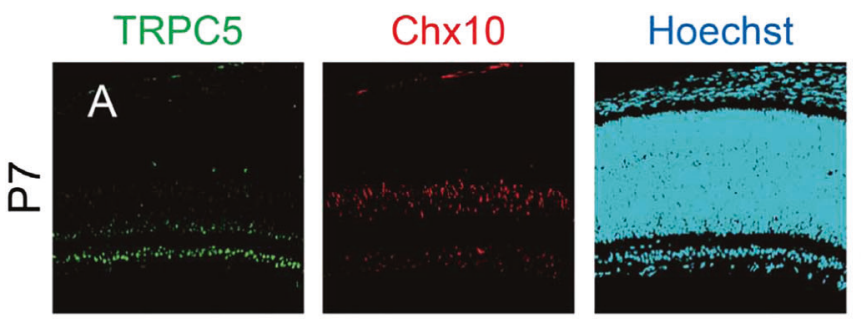

\section{Merged}
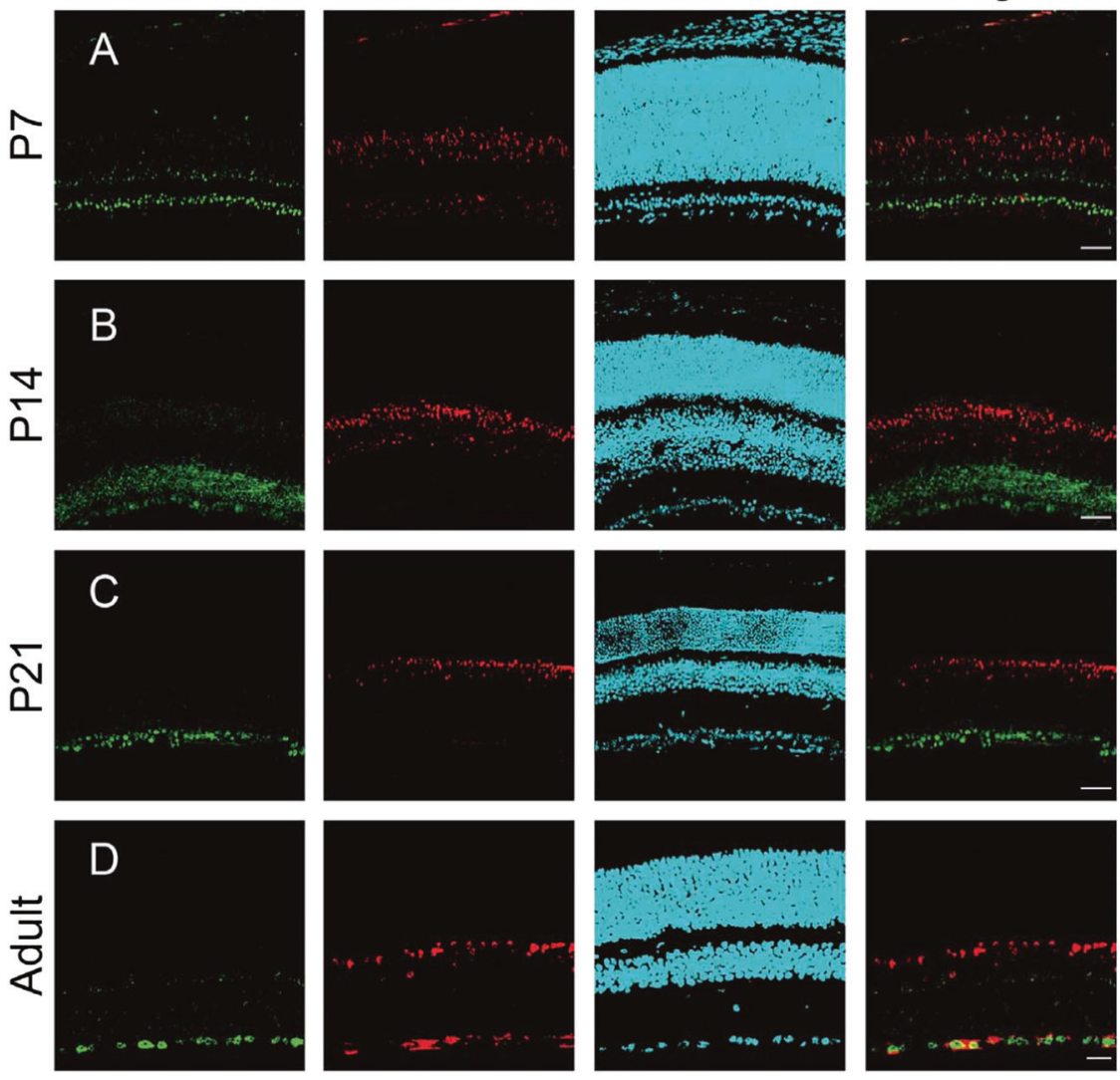

TRPC5

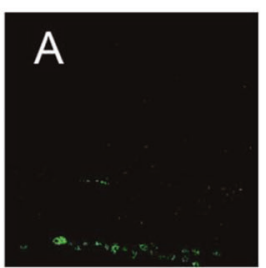

TRPC5

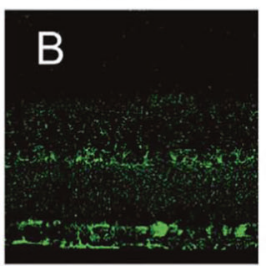

calbindin

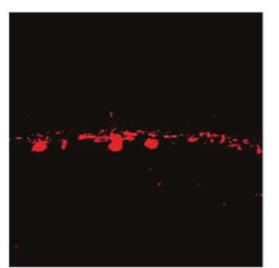

GS

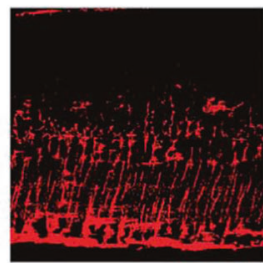

Hoechst

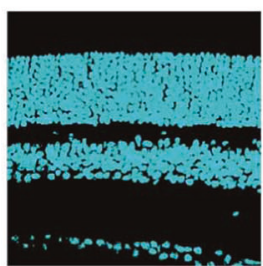

Hoechst

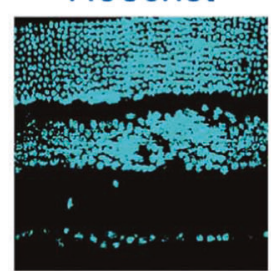

Merged

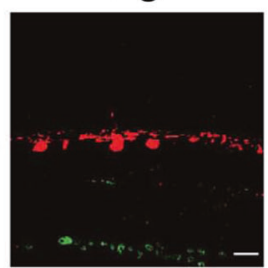

Merged

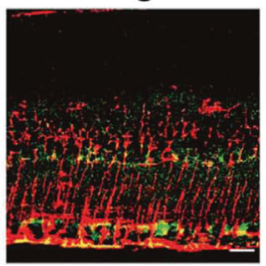

quantified the longest axon length in the RGCs. We then determined the differences in axonal outgrowth between control and inhibitor treated RGCs. Compared with controls, clemizole treatment significantly enhanced axonal outgrowth (Fig. 10a, b), suggesting that TRPC5 activation suppressed axonal outgrowth. In contrast to clemizoletreated cells, axon length in tranilast-treated RGCs was similar to control cells (Fig. 10a, b). We generated a histogram showing the proportion of varying axon lengths
(Fig. 10c). The histogram indicated that the percentage of short axons $(0-25 \mu \mathrm{m})$ was reduced (Fig. 10c), whereas the percentage of medium sized axons $(26-50 \mu \mathrm{m})$ was increased in clemizole-treated cells compared with control cells (Fig. 10c). Moreover, the population of longest axons $(>50 \mu \mathrm{m})$ was slightly increased in clemizole-treated cells. Hence, the shape of the histogram of clemizole-treated cells was shifted to the right compared with control cells (Fig. 10c). In contrast, the histogram of tranilast-treated 
Fig. 10 TRPC5 inhibition enhances axonal outgrowth in developing RGCs.

a Representative images of cultured RGCs. The TRPC5 antagonist clemizole $(10 \mu \mathrm{M})$ or the TRPV2 antagonist tranilast $(75 \mu \mathrm{M})$ were applied to the RGCs. After 4 days in culture, immunostaining for the RGC marker NF-M was performed. b Quantification of the longest axon lengths (control: $n=120$ cells; clemizole: $n=120$ cells; tranilast: $n=79$ cells).

c Histogram of axon lengths. Scale bar: $20 \mu \mathrm{m}$. $* * p<0.01$.
A

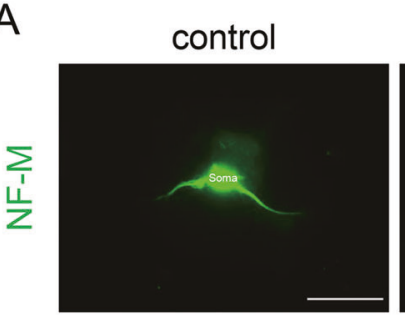

B

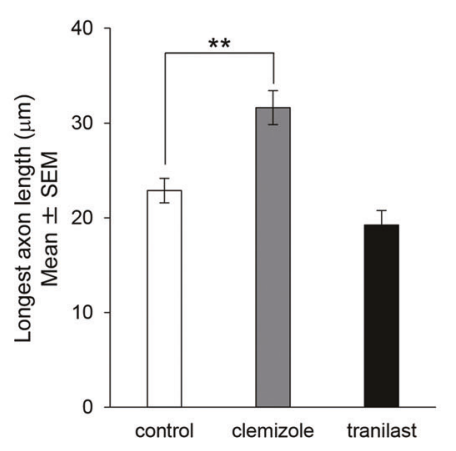

clemizole

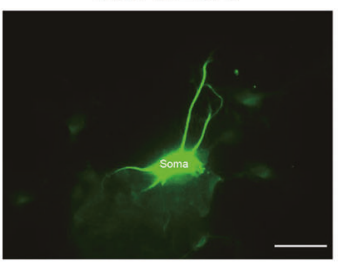

C

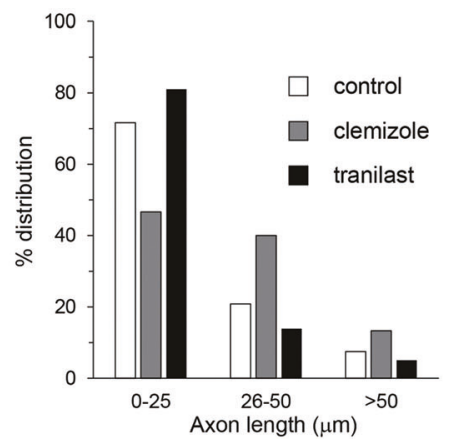

cells was unchanged. These results indicate that TRPC5 acts as a negative regulator of axon outgrowth in developing RGCs.

Next, we examined whether TRPC5-overexpression suppressed axonal outgrowth. We electroporated cDNA for EGFP alone (as a control) or TRPC5 + EGFP into the eye cup of E17.5 embryos. The axon length of TRPC5 + EGFP-overexpressing cells was shorter than that of EGFPoverexpressing cells (Fig. 11a). These results are consistent with previous findings in hippocampal neurons [28]. The histogram of TRPC5 + EGFP-overexpressing cell numbers indicated that the percentage of cell numbers bearing middle length axon $(50-100 \mu \mathrm{m})$ increased (Fig. 11b), whereas the percentage of cell numbers bearing long axon $(>100 \mu \mathrm{m})$ was reduced compared with EGFP-overexpressing cells. In contrast, the percentage of cell numbers bearing short axons $(0-50 \mu \mathrm{m})$ was unchanged (Fig. 11b). Moreover, the shape of the histogram of TRPC5 + EGFP-overexpressing cells shifted to the left compared with that of EGFPoverexpressing cells (Fig. 11b). Taken together with the clemizole results (Fig. 10), these results (Fig. 11) indicates that TRPC5 is an important negative regulator of RGC axonal outgrowth.

\section{Discussion}

Here, we found that retinal TRPC5 expression begins at E14.5 (Figs. 1 and 4), and is restricted to postmitotic neuronal precursors, ACs, and RGCs (Fig. 5). Notably, we revealed for the first time that developing and mature RGCs
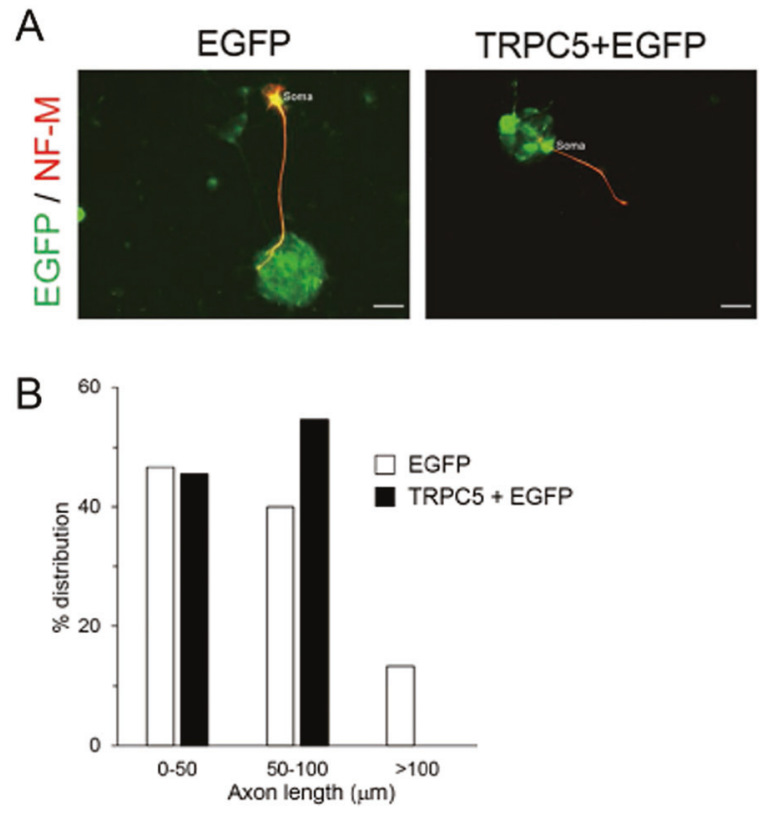

Fig. 11 Overexpression of TRPC5 suppresses axonal outgrowth in developing RGCs. a Representative images of EGFP or TRPC5 + EGFP-expressing RGCs. After 4 days in culture, immunostaining for EGFP and the RGC marker NF-M was performed. b Histogram of axon lengths (EGFP: $n=15$ cells; TRPC5 + EGFP: $n=22$ cells). Scale bar: $20 \mu \mathrm{m}$.

strongly express TRPC5 (Figs. 1-6) distinct from previous reports in the chick retina [29]. TRPC5 expression is then observed in Müller glial cells in addition to RGCs and ACs later during development (Figs. 1-9). Based on these findings, we focused on the function of TRPC5 in RGC development. It was reported that TRPC5 negatively 
regulates axonal outgrowth in hippocampal neurons [28]. Therefore, we hypothesized that TRPC5 might have similar functions in RGCs since they extend very long axons toward the brain, and this characteristic is significantly different from other retinal cell types. To test this, we inhibited TRPC5 in developing RGCs which resulted in significantly increased RGC axon length (Fig. 10). Conversely, overexpression of TRPC5 inhibited axonal outgrowth in developing RGCs (Fig. 11). These results indicate that TRPC5 is an important negative regulator of RGC axonal outgrowth similar to hippocampal neurons [28].

We previously reported that TRPV2 promotes axonal outgrowth in a membrane stretch dependent manner $[32,38]$. In addition to our report, it has also been suggested that TRPV1 and TRPV4 have similar functions [39, 40]. Furthermore, the activity of TRPC1, TRPC3, or TRPC6 was shown to be required for nerve growth cone guidance by netrin- 1 or BDNF $[41,42]$. Hence, these TRP channels are positive regulators of axonal outgrowth. In contrast, TRPC5 has the opposing effect of suppressing axonal outgrowth and acting as a negative regulator (Figs. 10 and 11). Combined with the present results, these studies demonstrate that the balance between positive regulators and TRPC5 is important for neuronal circuit formation. This also leads us to conclude that TRPC5 activation is advantageous for elongating axons, because it enables them to better sense netrin-1 or BDNF by tempering their axonal outgrowth via TRPC5. These periods of suspended growth caused by TRPC5 can evoke further driving force for axonal outgrowth. Therefore, TRPC5 might amplify the rate of axonal outgrowth in cooperation with TRPV2 [32] and other factors.

This leaves the question as to how TRPC5 is activated in developing RGCs. In our study, we found that serum application significantly elevated intracellular $\mathrm{Ca}^{2+}$ levels (Fig. 5d), and TRPC5 inhibition partially inhibited this serum-induced elevation in intracellular $\mathrm{Ca}^{2+}$ levels (Fig. 5d). Hence, some trophic factors found within the serum might activate TRPC5 in developing RGCs. It was reported that TRPC5 inhibited NGF-induced axonal outgrowth [43], suggesting that NGF is a candidate for the TRPC5 activator. It is well known that the PLC signaling cascade activates TRPC5 [22], thus the PLC pathway can be activated by NGF. As described above, we previously reported that the movement of growth cones generates membrane stretch, and this stretch activates TRPV2 [44, 45] which promotes axonal outgrowth [32]. Thus the mechanosensing function of TRPV2 regulates neuronal circuit formation. TRPC5 also possesses mechanosensory function [24]; therefore, membrane stretch might also be an activator of TRPC5 in RGCs. TRPC5 has also been shown to be activated by cold temperatures $\left(<37^{\circ} \mathrm{C}\right)$ [25]. Specifically, TRPC5 is very sensitive to physiological temperature ranges. Thus, in regions where tissue is cooler, TRPC5 might be activated based on its temperature. Indeed, we recently reported that the adult brain has regional temperature diversity dependent on cell type, which was determined by measuring cell-specific intracellular temperatures [45]. Based on our results, the temperature of some regions is $2-3^{\circ} \mathrm{C}$ cooler than other regions in the adult brain [45]. Hence, developing tissues might show alternative patterns of unique temperature distribution, and cooler temperatures could activate TRPC5 in RGCs. TRPC5 has also been identified as a NO sensor protein [23]. Previous studies revealed that NO contributes to the switch from cell proliferation to differentiation during neurogenesis [46]. Thus, NO might affect axonal outgrowth through TRPC5 activation in developing RGCs.

In the adult mouse retina, TRPC5 expression was observed in most RGCs (Fig. 6) and a subset of ACs (Fig. 7). In the chick retina, it was reported that NO activates TRPC5, and increases intracellular $\mathrm{Ca}^{2+}$ levels. This triggers the release of GABA from the ACs [29]. These results suggest that TRPC5 activation modulates visual signaling by enhancing GABAergic inhibition. A similar mechanism may be at work in mouse ACs and RGCs during visual processing. The roles of TRPC5 in mature neurons are still not fully understood. In the brain, TRPC5 activation in mature neurons is associated with fear processing in the amygdala [47]. Hence, TRPC5 expression in RGCs may regulate neuronal excitability responses to visual information. Further studies will clarify the involvement of TRPC5 in these processes.

Excessive mechanical stress reduces the viability of cells in the visual system. Glaucoma, a visual impairment disease, is associated with pathological mechanical stress in the eye [48]. Significant positive correlations between intraocular pressure and RGC loss have been reported in glaucoma animal models as well as in patients $[49,50]$. In glaucoma, $\mathrm{Ca}^{2+}$ influx is evoked by activation of mechanosensitive ion channels, which is proposed to influence the dendritic and axonal remodeling of RGCs that may lead to cell death [48]. RGCs themselves are highly sensitive to mechanical forces [48]. A recent study raised the possibility of TRPV4 as a candidate for the glaucoma mechanosensor [51]. Very recently, we reported that TRPV4 is a critical mechanosensory ion channel in Müller glial cells at body temperature [52]. The swelling of Müller glial cells by retinal detachment causes excessive activation of TRPV4 and the release of MCP-1; this results in the accumulation of microglia near the photoreceptors, and subsequent death of the photoreceptors [52]. As described above, TRPC5 is also a mechanosensitive ion channel [24]. Hence, TRPC5 may sense the abnormal intraocular pressure in glaucoma and lead to the death of RGCs. In this case, the excessive $\mathrm{Ca}^{2+}$ influx through TRPC5 can evoke dendritic and axonal 
remodeling, and this may lead to cell death, as our data clearly indicate that TRPC5 is an important regulator of neurite remodeling (Figs. 10 and 11). Future studies will reveal the molecular mechanisms as to how TRPC5 localized to RGCs senses the abnormal intraocular pressure in glaucoma as suggested by our findings.

Acknowledgements We thank Mrs. K. Abe (Gunma Univ.) and Mrs. Y. Kogure (Gunma Univ.) for technical assistance and our lab members for helpful discussions. This study was supported by Grantsin-Aid for Scientific Research from the Takeda Science Foundation, Sumitomo Foundation, the Brain Science Foundation, Narishige Neuroscience Research Foundation, Salt Science Research Foundation No.14C2, the Ichiro Kanehara Foundation, Takano Life Science Research Foundation, MEXT/JSPS KAKENHI JP15H05934<Thermal Biology>, JP15H03000, JP18H03124, JP18K19418 (all to KS), and JP $18 \mathrm{H} 02522$ (to YI).

\section{Compliance with ethical standards}

Conflict of interest The authors declare that they have no conflict of interest.

Publisher's note Springer Nature remains neutral with regard to jurisdictional claims in published maps and institutional affiliations.

\section{References}

1. Young RW. Cell differentiation in the retina of the mouse. Anat Rec. 1985;212:199-205.

2. Rapaport DH, Wong LL, Wood ED, Yasumura D, LaVail MM. Timing and topography of cell genesis in the rat retina. J Comp Neurol. 2004;474:304-24.

3. Benson DL, Colman DR, Huntley GW. Molecules, maps and synapse specificity. Nat Rev Neurosci. 2001;2:899-909.

4. Lu DC, Niu T, Alaynick WA. Molecular and cellular development of spinal cord locomotor circuitry. Front Mol Neurosci. 2015;8:25.

5. Raper J, Mason C. Cellular strategies of axonal pathfinding. Cold Spring Harb Perspect Biol. 2010;2:a001933.

6. Tessier-Lavigne M, Goodman CS. The molecular biology of axon guidance. Science. 1996;274:1123-33.

7. Chilton JK. Molecular mechanisms of axon guidance. Dev Biol. 2006;292:13-24.

8. Gomez TM, Spitzer NC. Regulation of growth cone behavior by calcium: new dynamics to earlier perspectives. J Neurobiol. 2000;44:174-83.

9. Gomez TM, Zheng JQ. The molecular basis for calciumdependent axon pathfinding. Nat Rev Neurosci. 2006;7:115-25.

10. Nilius B. TRP channels in disease. Biochim Biophys Acta. 2007;1772:805-12.

11. Clapham DE. TRP channels as cellular sensors. Nature. 2003;426:517-24.

12. Voets T, Talavera K, Owsianik G, Nilius B. Sensing with TRP channels. Nat Chem Biol. 2005;1:85-92.

13. Damann N, Voets T, Nilius B. TRPs in our senses. Curr Biol. 2008;18:R880-9.

14. Talavera K, Nilius B, Voets T. Neuronal TRP channels: thermometers, pathfinders and life-savers. Trends Neurosci. 2008;31:287-95.

15. Dhaka A, Viswanath V, Patapoutian A. Trp ion channels and temperature sensation. Annu Rev Neurosci. 2006;29:135-61.
16. Venkatachalam K, Montell C. TRP channels. Annu Rev Biochem. 2007;76:387-417.

17. Zhu X, Chu PB, Peyton M, Birnbaumer L. Molecular cloning of a widely expressed human homologue for the Drosophila trp gene. FEBS Lett. 1995;373:193-8.

18. Ramsey IS, Delling M, Clapham DE. An introduction to TRP channels. Annu Rev Physiol. 2006;68:619-47.

19. Philipp S, Hambrecht J, Braslavski L, Schroth G, Freichel M, Murakami M, et al. A novel capacitative calcium entry channel expressed in excitable cells. EMBO J. 1998;17:4274-82.

20. Schaefer M, Plant TD, Obukhov AG, Hofmann T, Gudermann T, Schultz G. Receptor-mediated regulation of the nonselective cation channels TRPC4 and TRPC5. J Biol Chem. 2000; 275:17517-26.

21. Kanki H, Kinoshita M, Akaike A, Satoh M, Mori Y, Kaneko S. Activation of inositol 1,4,5-trisphosphate receptor is essential for the opening of mouse TRP5 channels. Mol Pharmacol. 2001;60:989-98.

22. Putney JW Jr. The enigmatic TRPCs: multifunctional cation channels. Trends Cell Biol. 2004;14:282-6.

23. Yoshida T, Inoue R, Morii T, Takahashi N, Yamamoto S, Hara Y, et al. Nitric oxide activates TRP channels by cysteine Snitrosylation. Nat Chem Biol. 2006;2:596-607.

24. Gomis A, Soriano S, Belmonte C, Viana F. Hypoosmotic- and pressure-induced membrane stretch activate TRPC5 channels. J Physiol. 2008;586:5633-49.

25. Zimmermann K, Lennerz JK, Hein A, Link AS, Kaczmarek JS, Delling M, et al. Transient receptor potential cation channel, subfamily C, member 5 (TRPC5) is a cold-transducer in the peripheral nervous system. Proc Natl Acad Sci USA. 2011; 108:18114-9.

26. Strubing C, Krapivinsky G, Krapivinsky L, Clapham DE. TRPC1 and TRPC5 form a novel cation channel in mammalian brain. Neuron. 2001;29:645-55.

27. Ambudkar IS, Ong HL. Organization and function of TRPC channelosomes. Pflugers Arch. 2007;455:187-200.

28. Greka A, Navarro B, Oancea E, Duggan A, Clapham DE. TRPC5 is a regulator of hippocampal neurite length and growth cone morphology. Nat Neurosci. 2003;6:837-45.

29. Maddox JW, Khorsandi N, Gleason E. TRPC5 is required for the NO-dependent increase in dendritic $\mathrm{Ca}(2+)$ and GABA release from chick retinal amacrine cells. J Neurophysiol. 2018; 119:262-73.

30. Witkovsky P, Gabriel R, Krizaj D. Anatomical and neurochemical characterization of dopaminergic interplexiform processes in mouse and rat retinas. J Comp Neurol. 2008;510:158-74.

31. Gilliam JC, Wensel TG. TRP channel gene expression in the mouse retina. Vis Res. 2011;51:2440-52.

32. Shibasaki K, Murayama N, Ono K, Ishizaki Y, Tominaga M. TRPV2 enhances axon outgrowth through its activation by membrane stretch in developing sensory and motor neurons. J Neurosci. 2010;30:4601-12.

33. Marquardt T, Gruss P. Generating neuronal diversity in the retina: one for nearly all. Trends Neurosci. 2002;25:32-8.

34. Shibasaki K, Takebayashi H, Ikenaka K, Feng L, Gan L. Expression of the basic helix-loop-factor Olig2 in the developing retina: Olig2 as a new marker for retinal progenitors and late-born cells. Gene Expr Patterns. 2007;7:57-65.

35. Richter JM, Schaefer M, Hill K. Clemizole hydrochloride is a novel and potent inhibitor of transient receptor potential channel TRPC5. Mol Pharmacol. 2014;86:514-21.

36. Hisanaga E, Nagasawa M, Ueki K, Kulkarni RN, Mori M, Kojima I. Regulation of calcium-permeable TRPV2 channel by insulin in pancreatic beta-cells. Diabetes. 2009;58:174-84. 
37. McCabe KL, Gunther EC, Reh TA. The development of the pattern of retinal ganglion cells in the chick retina: mechanisms that control differentiation. Development. 1999;126:5713-24.

38. Shibasaki K. Physiological significance of TRPV2 as a mechanosensor, thermosensor and lipid sensor. J Physiol Sci. 2016;66:359-65.

39. Frey E, Karney-Grobe S, Krolak T, Milbrandt J, DiAntonio A. TRPV1 Agonist, Capsaicin, Induces Axon Outgrowth after Injury via Ca2+/PKA Signaling. eNeuro. 2018;5(3):ENEURO.0095-18.

40. Jang Y, Jung J, Kim H, Oh J, Jeon JH, Jung S, et al. Axonal neuropathy-associated TRPV4 regulates neurotrophic factorderived axonal growth. J Biol Chem. 2012;287:6014-24.

41. Shim S, Goh EL, Ge S, Sailor K, Yuan JP, Roderick HL, et al. XTRPC1-dependent chemotropic guidance of neuronal growth cones. Nat Neurosci. 2005;8:730-5.

42. Li Y, Jia YC, Cui K, Li N, Zheng ZY, Wang YZ, et al. Essential role of TRPC channels in the guidance of nerve growth cones by brain-derived neurotrophic factor. Nature. 2005;434:894-8.

43. Kumar S, Chakraborty S, Barbosa C, Brustovetsky T, Brustovetsky N, Obukhov AG. Mechanisms controlling neurite outgrowth in a pheochromocytoma cell line: the role of TRPC channels. J Cell Physiol. 2012;227:1408-19.

44. Sugio S, Nagasawa M, Kojima I, Ishizaki Y, Shibasaki K. Transient receptor potential vanilloid 2 activation by focal mechanical stimulation requires interaction with the actin cytoskeleton and enhances growth cone motility. FASEB J. 2017;31:1368-81.

45. Hoshi Y, Okabe K, Shibasaki K, Funatsu T, Matsuki N, Ikegaya $\mathrm{Y}$, et al. Ischemic Brain Injury Leads to Brain Edema via
Hyperthermia-Induced TRPV4 Activation. J Neurosci. 2018;38:5700-9.

46. Gibbs SM. Regulation of neuronal proliferation and differentiation by nitric oxide. Mol Neurobiol. 2003;27:107-20.

47. Riccio A, Li Y, Moon J, Kim KS, Smith KS, Rudolph U, et al. Essential role for TRPC5 in amygdala function and fear-related behavior. Cell. 2009;137:761-72.

48. Križaj D, Ryskamp DA, Tian N, Tezel G, Mitchell CH, Slepak VZ, et al. From mechanosensitivity to inflammatory responses: new players in the pathology of glaucoma. Curr Eye Res. 2014;39:105-19.

49. Bonomi L, Marchini G, Marraffa M, Morbio R. The relationship between intraocular pressure and glaucoma in a defined population. Data from the Egna-Neumarkt Glaucoma Study. Ophthalmologica. 2001;215:34-8.

50. John SW, Smith RS, Savinova OV, Hawes NL, Chang B, Turnbull $\mathrm{D}$, et al. Essential iris atrophy, pigment dispersion, and glaucoma in DBA/2 J mice. Investig Ophthalmol Vis Sci. 1998;39:951-62.

51. Ryskamp DA, Witkovsky P, Barabas P, Huang W, Koehler C, Akimov NP, et al. The polymodal ion channel transient receptor potential vanilloid 4 modulates calcium flux, spiking rate, and apoptosis of mouse retinal ganglion cells. J Neurosci. 2011;31:7089-101.

52. Matsumoto H, Sugio S, Seghers F, Krizaj D, Akiyama H, Ishizaki Y, et al. Retinal detachment-induced Müller Glial cell swelling activates TRPV4 ion channels and triggers photoreceptor death at body temperature. J Neurosci. 2018;38:8745-58. 